\title{
Rehabilitation of an Edentulous Patient with Implant Supported Overdenture
}

\author{
Swapnali Mhatre, Sabita M Ram, Janani Mahadevan, Malika Karthik
}

\begin{abstract}
The conventional mandibular complete dentures are often associated with advanced ridge resorption and loss of retention. Dental implants in the anterior mandible were documented as being highly successful treatment option for overdenture. It has been use to improve the retention of mandibular dentures and also to improve patient's satisfaction. Because of high success rates, as well as lower costs, it is common to treat edentulous patients with just two implants and ball attachments for retention of the overdenture, instead of four implants and a bar. In this article a simple process of converting existing conventional denture into an implant supported overdenture by housing the retentive elements directly into the impression surface of the denture through a simple chairside technique is described.
\end{abstract}

Keywords: Overdenture, Implant, O-ring attachments.

How to cite this article: Mhatre S, Ram SM, Mahadevan J, Karthik M. Rehabilitation of an Edentulous Patient with Implant Supported Overdenture. J Contemp Dent 2013;3(1):52-56.

Source of support: Nil

Conflict of interest: None declared

\section{INTRODUCTION}

The overdenture treatment uses a removable complete denture that overlies retained teeth, tooth roots or dental implants. Practitioners have successfully used existing tooth structures or retained roots to assist the complete denture treatment for more than a century. ${ }^{1}$ However, the tooth-borne version of this treatment has some drawbacks like problems arising from dental caries, periodontal disease and technical problems associated with denture fabrication, denture fracture and the reality of working with a compromised, terminal dentition have made many practitioners reluctant to prescribe this treatment for their patients.

A successful long-term use of osseointegrated implants in treating edentulous subjects has been documented. ${ }^{2}$ Implant-supported overdentures retained by attachments are now an established treatment method. ${ }^{3}$ The most important aim of using implant for these patents is to improve retention of complete mandibular dentures and to improve patient's satisfaction. ${ }^{4-7}$ This treatment is less expensive as compared to fixed restorative treatments involving additional implants for edentulous patients. The recent thrust toward endosseous dental implants as the support and retention mechanism for mandibular overdenture treatment has occurred because of a number of important considerations. Implant overdenture treatment provides many benefits of conventional toothborne overdentures while negating some of the most troubling problems, such as tooth decay and periodontal disease. ${ }^{1}$ Dental implants provide a mechanism for establishing a foundation for overdenture treatment, even after all the teeth have been removed. Implants allow practitioners to regain lost supporting structures for edentulous patients already using conventional complete dentures. Finally, the outcome of implant overdenture treatment is predictably and significantly better than that of conventional complete denture treatment. ${ }^{6,7}$

The mandible is well suited for implant-retained overdentures, particularly when the implants were placed in the intercanine regions. Various attachment systems were used among which, ball attachments have been proven to be reliable. ${ }^{8,9}$ The ball attachment consists of a spherical patrix that is screwed into the implant assembly. The matrix fits over the patrix and provides retention by means of spring-action arms or an interchangeable elastic ring. The connection between the matrix and the denture can be achieved by indirect or direct method.

This article describes a clinical procedure for a direct connection between a complete mandibular overdenture and two supraimplant nonsplinted ball attachments. This method prevents compression of the gingival peri-implant soft tissue, and allows the denture to be seated completely on the supporting surface.

\section{CASE REPORT}

A 65-year-old male patient reported to the Department of Prosthodontics with the chief complaint of loose lower complete denture prosthesis. The patient was unable to eat or speak properly as the lower denture was loose (Fig. 1).

The patient gave a history of losing his teeth 5 years back due to caries and periodontal disease. He has been using his current set of dentures for the past 2 months and has the complaint of loose mandibular complete denture. Clinical examination revealed that the patient has completely edentulous upper and lower arches. The ridge was U shaped, smooth with no irregularities, no bony spicules or root pieces, but the mandibular ridge was found to be resorbed. However, the maxillary ridge was favorable for conventional denture construction.

Maxillary and mandibular diagnostic casts were made, a panoramic radiograph were taken to assess the bone for 
selection of implants. Radiographic examination of the patient showed that the patient had dense compact bone in the mandibular anterior region without any pathology (Figs 2 and 3). The blood reports of the patient also were checked to rule out any pathology. He had been informed about the possible treatment options that is fixed implant supported prosthesis with 6/8 implants and removable implant supported prosthesis with 2/4 implants available with implant therapy. Patient opted for placement of two one piece dental implants with ball attachment on the mandibular arch and overdenture over it.

\section{CLINICAL PROCEDURE}

The existing denture of the patient was recently fabricated and was found to be satisfactory in occlusion, stability and esthetics. Hence, the same prosthesis was used for the conversion into implant supported overdenture prosthesis. Mandibular complete denture was duplicated with clear acrylic to form the radiographic stent. Gutta-percha markers were place in stent at proposed implantation site (Fig. 4) Dentascan was used to identify the sites for the implant placement, bone height and width. This stent was then used as surgical stent (Fig. 5).

With the help of lower complete denture prosthesis surgical stent the implant sites were marked in patient mouth. Two one piece implants of size $3.8 \times 13 \mathrm{~mm}$ with ball attachments (myride snap) were placed in mandible between mental foramen with open method, sequential drilling to prepare implant site and maintaining sterile surgical protocol (Fig. 6). The mandibular denture was relieved from the area where the implants were placed so that it could be seated passively over the top of ball attachment of implants. Denture was lined by a soft reliner (Coe-Soft Reliner, Dentsply) in the area of implant so that patient can use prosthesis immediately after surgery (Fig. 7).

After 3 months of implant placement, the liner placed on the tissue surface of the denture was removed (Figs 8 and 9). The patient's prosthesis was carefully examined to ensure passive fit. Neck of O-ring attachment (undercut area) was blocked by placing rubber disk or separator. The retentive elements or keeper caps for the implant abutment were housed directly into the fitting surface of the denture with the help of autopolymerizing resin (Dentsply Repair Material). A standard chairside autopolymerizing resin mix was then prepared and placed into the denture. Denture was placed and the patient was asked to close in function over the implants with the keeper caps attached. Denture was removed from the patient's mouth just before final set; excess acrylic material removed and replaced back to final set. After fishing and polishing of denture containing the keeper caps occlusal equilibration was done intraoraly
(Figs 10 and 11). The final prosthesis appeared to improve retention and chewing ability of patient (Fig. 12).

\section{DISCUSSION}

A successful long-term use of two osseointegrated implants in treating edentulous subjects has been documented. Van Steenbergheet, was among the pioneer to propose placement

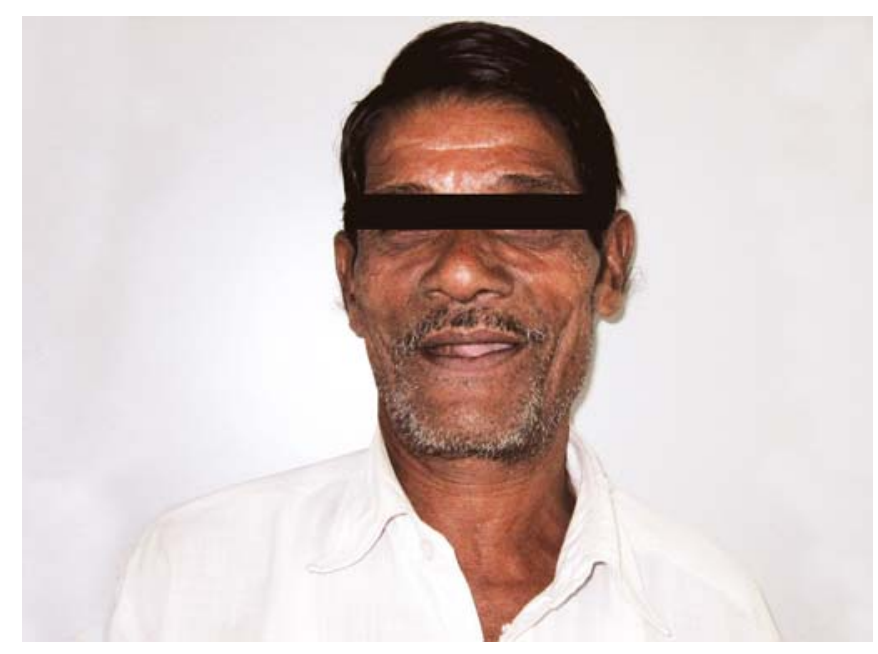

Fig. 1: Preoperative extraoral

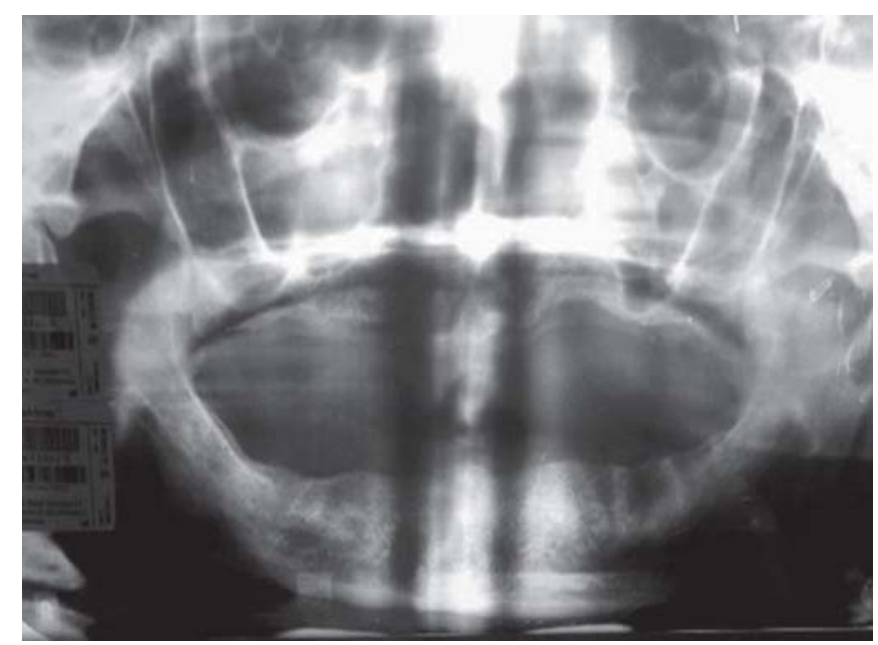

Fig. 2: Orthopantamograph showing edentulous arches

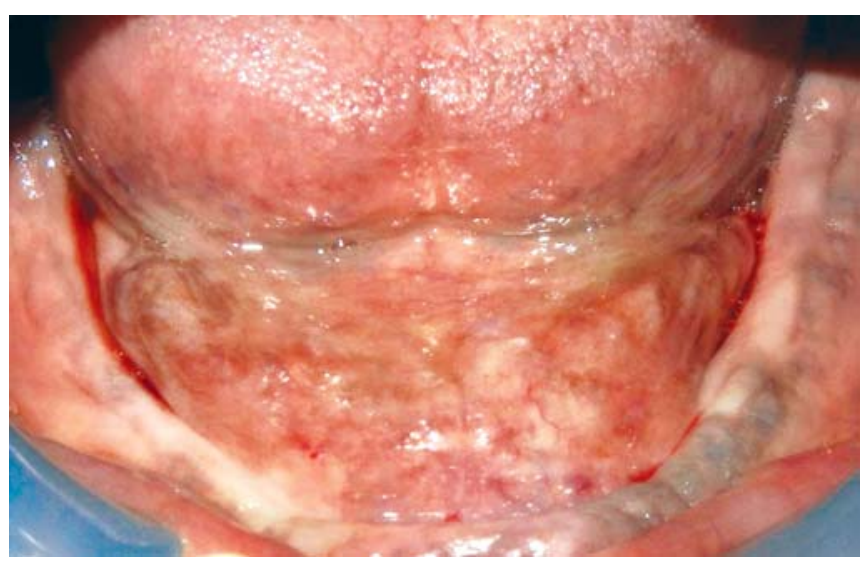

Fig. 3: Mandibular residual alveolar ridge 
of only two implants in the edentulous mandible. ${ }^{10} \mathrm{He}$ observed $98 \%$ success rate with up to 52 months of followup. Naert, compared the clinical outcome of different overdenture anchorage systems and found 100\% implant success after 5 years for all groups. ${ }^{11}$

In this article conventional complete denture prosthesis was converted into implant supported overdenture prosthesis at a comparatively low cost without compromising esthetic

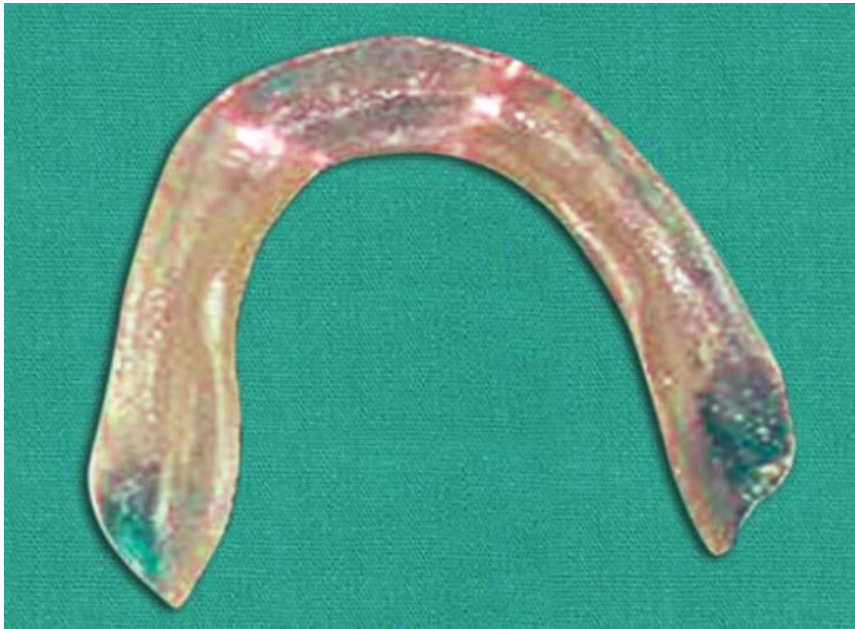

Fig. 4: Radiographic stent with gutta-percha points

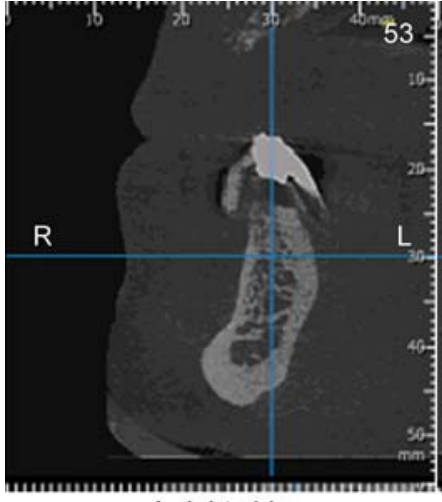

A-right side

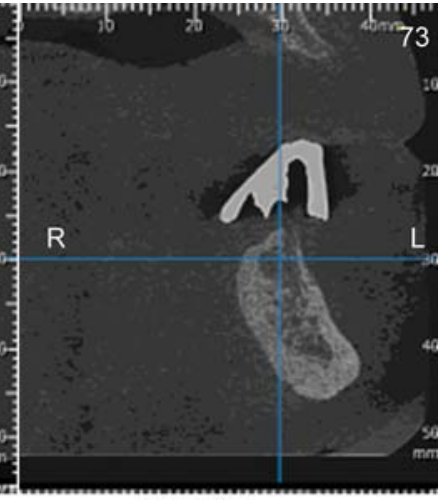

B-left side
Fig. 5: Dentascan slice showing site marked with gutta-percha point

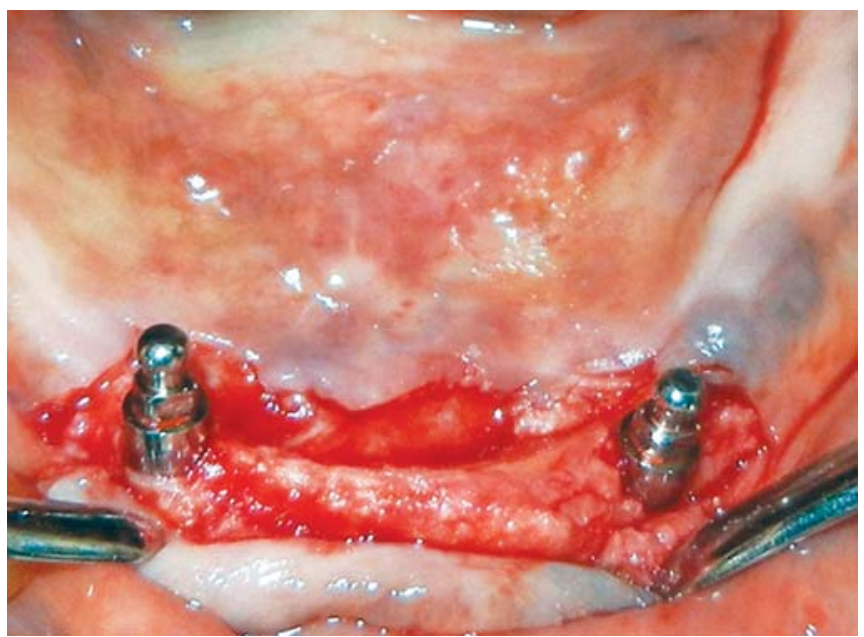

Fig. 6: One piece dental implants with ball attachment and function. An implant supported fixed prosthesis would require placement of more number of implants and hence, the cost of the treatment increases. Also with this procedure, the prosthesis can be fabricated with materials that are readily available and familiar. In a study done by Li Chen, the patients in the comparative masticatory efficiency test restored with implant-supported overdentures and toothsupported overdentures showed higher comparative masticatory efficiency than those restored with conventional complete dentures. ${ }^{12}$

The implant supported overdenture prosthesis helps in preservation of alveolar bone. Crum and Rooney have found that the reduction in the height of anterior part of the mandible in those patients wearing complete upper and lower dentures amounted to $5.2 \mathrm{~mm}$ as compared with $0.6 \mathrm{~mm}$ for the overdenture patients. ${ }^{13}$ The anterior mandible bone under an implant overdenture may resorbed as little as $0.5 \mathrm{~mm}$ over a 5-year period, and long-term resorption may remain at $0.1 \mathrm{~mm}$ annually. ${ }^{12,14,15}$ Same is true for fixed implant complete denture. ${ }^{5}$ LoCascio and Salinas ${ }^{16}$ for a conventional implant supported mandibular complete denture, recommended $15 \mathrm{~mm}$ of space measured from the crest of the mandibular ridge to the opposing dentition at a correct vertical dimension of occlusion, whereas, William recommended $17 \mathrm{~mm}$ space for an overdenture supported by framework, this is an additional $2 \mathrm{~mm}$ (for the fixed frame). ${ }^{17}$ The case presented in this article had $15 \mathrm{~mm}$ of interarch space available.

The connection between retentive element and the denture can be achieved by indirect or direct method. The indirect technique consists of recording the denture's soft tissue support as well as positioning the implants in relation to the denture, so that the connection of the matrix and the relining procedure can be completed in the laboratory. This method has the potential advantages of reduced chair time

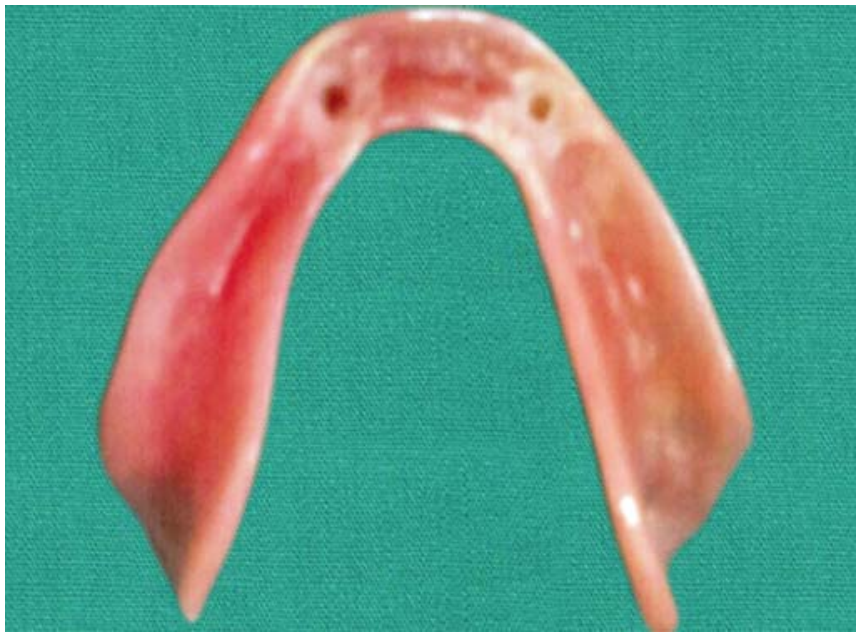

Fig. 7: Soft liner at the area of attachments 


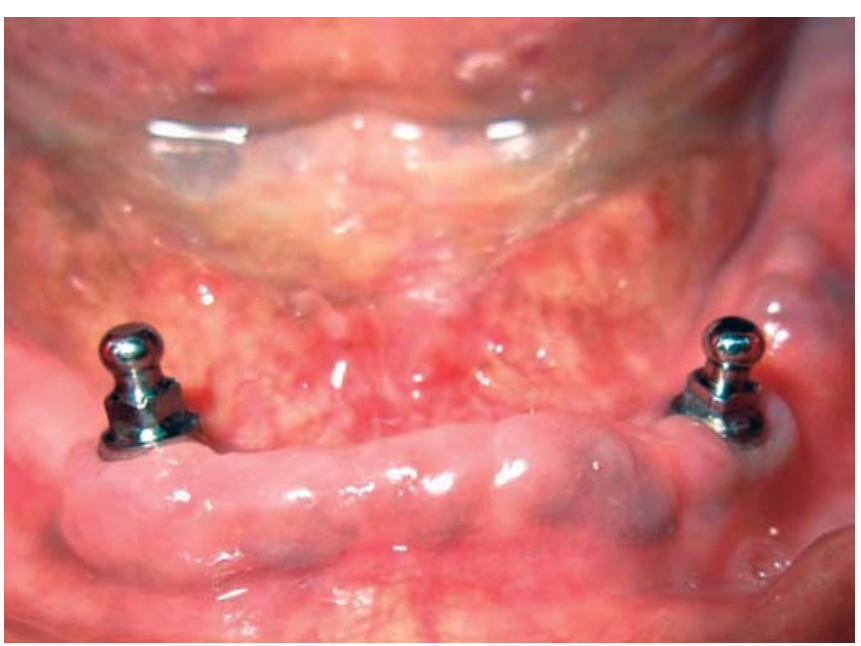

Fig. 8: Implants 3 months after surgery

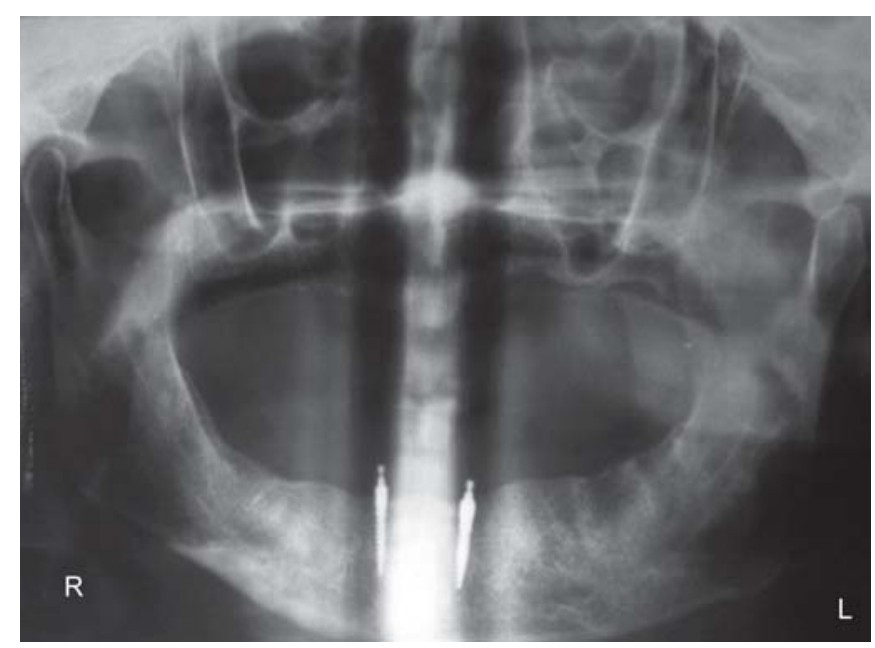

Fig. 9: OPG showing implants 3 months after surgery

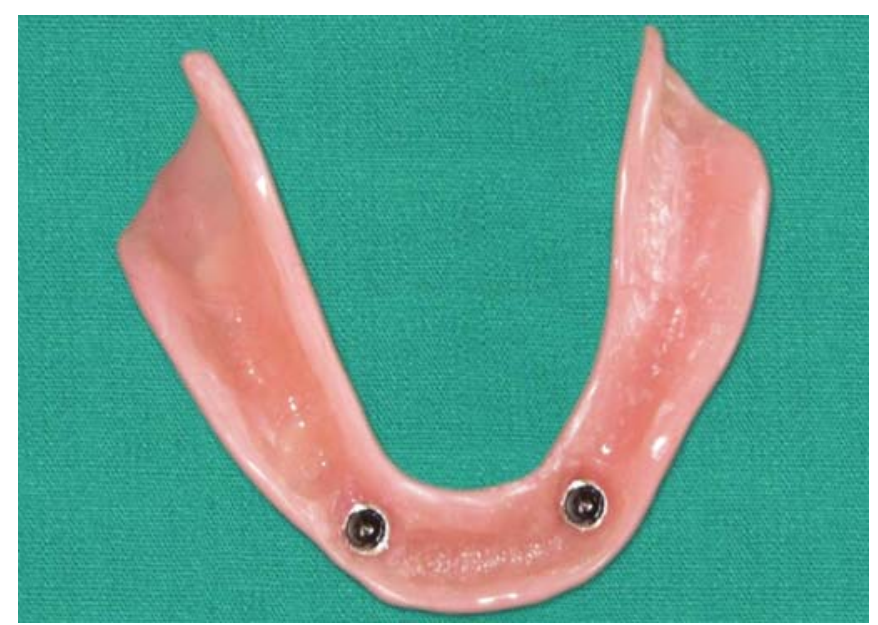

Fig. 10: Denture impression surface with retentive caps

and the use of a single denture base acrylic resin. However, the recording and transferring of the implants position with analogs may introduce some error. Moreover, the patient is without the prosthesis during this time. The direct technique for locating a ball attachment intraorally is simple, economic, quick, and allows the patient to retain the

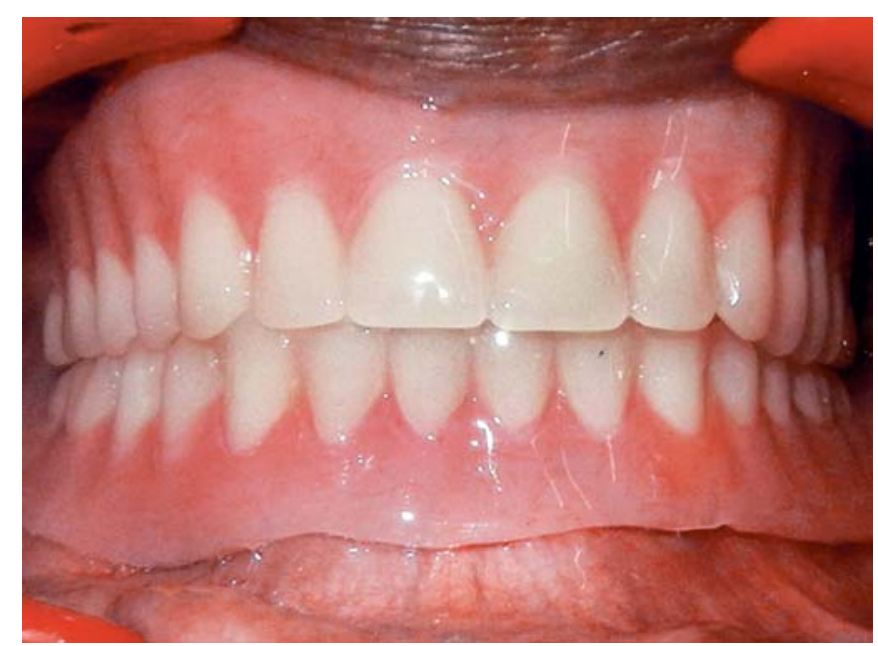

Fig. 11: Denture insertion

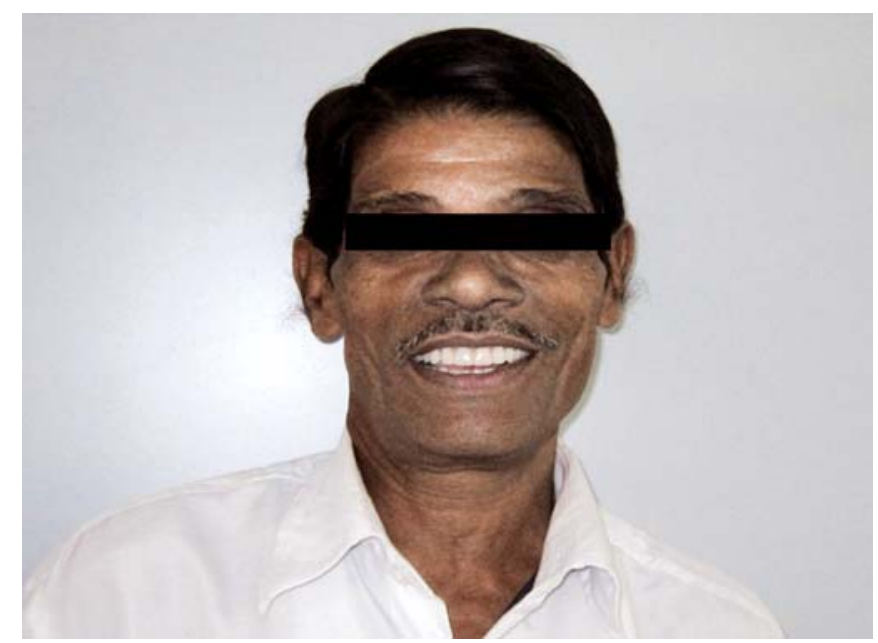

Fig. 12: Postoperative extraoral

prosthesis. If relining of the prosthesis is indicated, it should be completed as a preliminary step. ${ }^{9}$

Bulent, described a pressure free technique to provide the accurate relation of the implant components and the supporting tissues without finger pressure. ${ }^{18}$ However, it is technique sensitive and the clinician must assure the accurate placement of the attachments on the implant abutments during the impression process. Bulent and Volkan described a two stage impression technique that records the alveolar mucosa in a functional state and implant components accurately. ${ }^{19}$ The disadvantage of this technique is that it is time consuming compared with direct techniques. The direct technique described in this article is less technique sensitive and less time consuming provided the implants are placed accurately parallel to each other.

A photoelastic analysis done by Kenney and Richards indicated that the ball/O-ring attachment transferred less stress to the implants. ${ }^{20}$ It appears that the O-ring provide retention against dislodging forces toward occlusal surface, allowing the overdenture to rotate around the ball connected to the implant body. As rotation occurred, stress was 
transferred to the posterior edentulous area providing optimal broad stress distribution to the ridge and minimal stress to the implants. Thus, the mandibular overdenture retained by implants in the interforaminal region appears to maintain bone in anterior mandible and appeared to improve retention, stability and chewing ability. When two implants were used in the anterior mandible to retain an overdenture, solitary ball attachments appear to be less costly, less technique sensitive and more accommodating for tapered arches.

\section{CONCLUSION}

The mandibular overdentures retained by two ball attachments supported by two endosseous implants provides retention for the less retentive mandibular denture prosthesis due to deficient mandibular foundation and also improves the oral health related quality of life of the edentulous subject. It represents a case of an edentulous patient looking for low-cost improvement of denture retention. Significantly fewer visits for adjustment related to postplacement pressure spots were required for mandibular overdentures than for conventional mandibular prostheses.

\section{REFERENCES}

1. Fenton AH. The decade of overdentures: 1970-1980. J Prosthet Dent 1998;79(1):31-36.

2. Mericske-Stern R, Steinlin Schaffner T, Marti P, Geering AH. Peri-implant mucosal aspects of ITI implants supporting overdentures. A five-year longitudinal study. Clin Oral Implants Res 1994;5:9-18.

3. Feine JS, de Grandmont P, Boudrias P, Brien N, LaMarche C, Tache R, Lund JP. Within-subject comparisons of implantsupported mandibular prostheses: Choice of prosthesis. J Dent Res 1994;73:1105-11.

4. Blomberg S. Psychological response. In: Brånemark PI, Zarb GA, Albrektsson T (Eds). Tissue integrated prostheses. Chicago: Quintessence 1985;165-74.

5. Hoogstraten J, Lamers LM. Patient satisfaction after insertion of an osseointegrated implant bridge. J Oral Rehabil 1987;14: 481-87.

6. Burns DR, Unger JW, Elswick RK Jr, Giglio JA. Prospective clinical evaluation of mandibular implant overdentures: Part IIPatient satisfaction and preference. J Prosthet Dent 1995;73: 364-69.

7. Feine JS, Carlsson GE, Awad MA, Chehade A, Duncan WJ, Gizani S, et al. The McGill consensus statement on overdentures. Int J Oral Maxillofac Implants 2002;17(4):601-02.

8. Donatsky O, Hillerup S. Non-submerged osseointegrated dental implants with ball attachments supporting overdentures in patients with mandibular alveolar ridge atrophy. A short-term follow-up. Clin Oral Implants Res1996;7:170-74.

9. Payne AG, Solomons YF. The prosthodontic maintenance requirements of mandibular mucosa-and implant-supported overdentures: A review of the literature. Int J Prosthodont 2000; 13:238-43.
10. Van Steenberghe D, Quirynen M, Callberson L, Demanet M. A prospective evaluation of the fate of 697 consecutive intraoral fixtures ad modum Branemark in the rehabilitation of edentulism. J Head Neck Pathol 1987;6:53-58.

11. Naert I, Gizani S, Vuylsteke M, van Steenberghe D. A 5-year randomized clinical trial on the influence of splinted and unsplinted oral implants in mandibular overdenture therapy. Part I: Peri-implant outcome. Clin Oral Implants Res 1998;9: 170-77.

12. Chen L, Xie Q, Feng H, Lin Y, Li J. The masticatory efficiency of mandibular implant supported overdentures as compared with tooth supported over-dentures and complete dentures. J Oral Implantol 2002;28:238-43.

13. Crum RJ, Rooney GE. Alveolar bone loss in overdenture: A 5-year study. J Prosthet Dent 1978;6:610-13.

14. Quirynen M, Naert I, van Steenberghe D, Dekeyser C, Callens A. Periodontal aspects of osseointegrated fixtures supporting a partial bridge. An up to 6-years retrospective study. J Clin Periodontol 1992;19:118-26.

15. Jemt T, Chai J, Harnett J, Heath MR, Hutton JE, Johns RB, et al. A 5-year prospective multicenter follow-up report on overdentures supported by osseointegrated implants. Int J Oral Maxillofac Implants 1996;11:291-98.

16. LoCascio SJ, Salinas TJ. Rehabilitation of an edentulous mandible with an implant supported prosthesis. Pract Periodontics Aesthet Dent 1997;9:357-70.

17. Golden WG, Wee AG, Danos TL, Cheng AC. Fabrication of a two piece superstructure for a fixed detachable implant supported mandibular complete denture. J Prosthet Dent 2000;2:205-09

18. Uludag B, Cogalan K, Polat S. An alternative impression technique for implant-retained overdentures with locator attachments. J Oral Implantol 2010;34:451-53.

19. Uludag B, Sahin V. A functional impression technique for implant supported overdenture: A clinical report. J Oral Implantol 2006;32:41-43.

20. Kenney R, Richards MW. Photoelastic stress patterns produced by implant-retained overdentures. J Prosthet Dent 1998 Nov; 80(5):559-64.

\section{ABOUT THE AUTHORS}

\section{Swapnali Mhatre (Corresponding Author)}

Lecturer, Department of Prosthodontics, MGM Dental College and Hospital, Kamothe, Navi Mumbai, Maharashtra, India, Phone: 9920456906, e-mail: dr.swapnali.m@gmail.com

\section{Sabita M Ram}

Dean and Head, Department of Prosthodontics, MGM Dental College and Hospital, Navi Mumbai, Maharashtra, India

\section{Janani Mahadevan}

Associate Professor, Department of Prosthodontics, MGM Dental College and Hospital, Navi Mumbai, Maharashtra, India

\section{Malika Karthik}

Lecturer, Department of Prosthodontics, MGM Dental College and Hospital, Navi Mumbai, Maharashtra, India 